\title{
Administration of inhaled medications during noninvasive ventilation and/or tracheostomy
}

\author{
Kathleen ASTURIAN ${ }^{1}$, Maria Angélica FERREIRA ${ }^{1}$ \\ ${ }^{1}$ Hospital de Clínicas of Porto Alegre \\ Corresponding author: Asturian K, asturiank@gmail.com \\ Submitted: 16-07-2019 Resubmitted:06-02-2020 Accepted: 10-03-2020 \\ Peer review: blind reviewers
}

\begin{abstract}
Objectives: To describe the clinical and demographic profile of hospitalized patients undergoing noinvasive ventilation (NIV) and/or tracheostomy (TQT) with prescription of the pressurized inhaler (pMDI) and the difficulties and interventions performed to adapt the inhalation technique. Methods: This is an observational, retrospective and descriptive study of a series of cases, carried out in three clinical units of a university hospital in the years 2017 and 2018. Results: We analyzed data from 25 patients who received NIV and/or TQT for whom guidance has been requested from the Inhalation Techniques Guidance and Training Group (GOTTI). Of these, 15 patients (60\%) were using NIV, 5 (20\%) were tracheostomized and 5 (20\%) were tracheostomized with NIV. The difficulties identified in these patients were insecurity in removing the support, preference for nebulization, adaptation of the pMDI to the cannula and asynchrony between the jet firing and the beginning of inspiration. Conclusions: The use of aero-chamber coupled to the pMDI and tidal volume were the mostly made interventions. Masks and guidelines on the access route to the ventilation system were adapted in most cases This group of patients has particularities and difficulties in the inhalation technique that justify a specific educational intervention by professionals with more in-depth knowledge in the area.
\end{abstract}

Keywords: administration, inhalation, respiratory therapy, noninvasive ventilation, tracheostomy.

\section{Administração de medicamentos inalatórios durante ventilação não-invasiva e/ou traqueostomia}

\begin{abstract}
Resumo
Objetivos: Descrever o perfil clínico e demográfico de pacientes hospitalizados submetidos à ventilação mecância não-invasiva (VNI) e/ou traqueostomia (TQT) com prescrição de inalador pressurizado (pMDI) e as dificuldades e intervenções realizadas para adequação da técnica inalatória. Métodos: Trata-se de um estudo observacional, retrospectivo e descritivo de uma série de casos, realizado em três unidades de internação clínica de um hospital universitário nos anos de 2017 e 2018. Resultados: Foram analisados dados de 25 pacientes recebendo VNI e/ou TQT para os quais foi solicitada orientação do Grupo de Orientação e Treinamento em Técnica Inalatória (GOTTI). Destes, 15 pacientes (60\%) estavam em uso de VNI, 5 (20\%) eram traqueostomizados e 5 (20\%) eram traqueostomizados com VNI. As dificuldades identificadas nestes pacientes foram insegurança em afastar o suporte, preferência por nebulização, adaptação do pMDI à cânula e assincronia entre o o disparo do jato e o começo da inspiração. Conclusões: O uso de aerocâmara acoplada ao pMDI e volume corrente foram intervenções, majoritariamente, realizadas. A adaptação de máscaras e orientações sobre a via de acesso ao sistema de ventilação foi feita na maioria dos casos. Esse grupo de pacientes tem particularidades e dificuldades na técnica inalatória que justificam uma intervenção educativa específica por profissionais com conhecimento mais aprofundado na área.
\end{abstract}

Palavras-chave: administração por inalação, terapia respiratória, ventilação não invasiva, traqueostomia.

\section{Introduction}

Noninvasive mechanical ventilation (NIV) is a type of ventilatory support in which the airway's interior is not directly accessed by ventilation devices; there is an external interface, usually a facial or nasofacial mask, which uses positive pressure in the inspiratory phase only or continuous. This mechanical ventilatory support may be indicated in the treatment of acute chronic obstructive pulmonary disease (COPD) in patients with an inability to maintain spontaneous ventilation, usually with associated hypercapnia. Besides, NIV can also be used after extubation, aiming at shortening the duration of invasive ventilation. ${ }^{1}$ In 
addition to nasal or orofacial masks, ventilatory support can be done by directly accessing the tracheal lumen through a tracheostomy (TCT). ${ }^{2-4}$ Since the drug treatment of people with chronic obstructive pulmonary diseases is based on the use of bronchodilators and corticoids via the inhalation route, patients with chronic respiratory diseases submitted to NIV usually receive a prescription of medication in nebulization or pressurized inhalers (pressurized metered dose inhaler - pMDI). On the other hand, it is of knowledge that the adequate inhalation technique is fundamental to improve pulmonary delivery, reduce oropharynx deposition and, consequently, improve treatment effectiveness. ${ }^{5}$ The concomitance of NIV (with or without TCT) and inhalation therapy makes the drug inhalation administration even more complex, often posing a challenge to healthcare professionals and patients themselves.

The Inhalation Technique Orientation and Training Group (Grupo de Orientação e Treinamento em Técnica Inalatória, GOTTI) is part of a university extension project in force at the Hospital de Clínicas of Porto Alegre since 2008, and provides bedside guidance for patients and their families, in addition to promoting training for the hospital's health professionals who assist patients with chronic respiratory problems.

The objective of this study was to describe the clinical and demographic profile of hospitalized patients undergoing NIV and/or tracheostomy using inhalation therapy with a pressurized inhaler. The specific objectives were to qualitatively identify the main difficulties regarding drug administration and to quantitatively describe the interventions that can improve the inhalation administration of drugs in this population of hospitalized patients.

\section{Methods}

It is an observational, retrospective and descriptive study of a series of cases. All patients meeting these criteria were included: over 18 years of age in NIV and/or tracheostomy with pressurized inhaler prescription, male and female, who were guided by a group of orientation and training in inhalation technique (GOTTI) in the period from 2017 to 2018 in the clinical hospitalization units of the Clinical Hospital of Porto Alegre. Patients who had discontinued pMDI treatment at the time of orientation were excluded.

The clinical and demographic data were collected from the electronic records and from the inhalation technique group's attendance records.. The recommended interventions and measures for the adequacy of the technique were collected at the time of orientation. For the tabulation of this information, a standardized form was used as a data collection instrument, which was tabulated in a spreadsheet prepared through the Microsoft Exce $^{\circledR}$ software. The observations made by the GOTTI regarding the main difficulties observed in the inhalation technique in this group of patients were recorded qualitatively.

The analysis of the data was made in a simplified way using the calculation of central tendency (mean and median) and dispersion (standard deviation) measures. As this study was not designed for hypothesis testing, no sample size calculation was performed. The chi-squared and ANOVA statistical tests were used for the means. The project was approved by the HCPA (Hospital de Clínicas of Porto Alegre) Ethics Committee (GPPG No. 08-061).

\section{Results}

In a period of 24 months, 328 patients were guided by the GOTTI in three hospitalization units of the Clinical Hospital of Porto Alegre and the pediatric emergency unit. After applying the inclusion and exclusion criteria, 25 patients were included, of which 15 (60\%) were female and $10(40 \%)$ male. The mean age of the group was $62 .{ }^{9}$ years and more than $65 \%$ of the patients were smokers or former smokers; 17 patients made previous use of home oxygen therapy or non-invasive ventilation. Only 19 patients had updated spirometry results, and the mean of forced expiratory volume in 1 second (FEV1) was 35.2\%, which is a severe limitation of airflow. ${ }^{6}$

The most prevalent respiratory disease was COPD, with $60 \%$ of the cases, followed by COPD associated with another comorbidity, such as Apnea Syndrome and Obstructive Sleep Hypopnea (ASOSH) and Asthma. Other diseases, as specified in Table 1, refer to other clinical conditions that led the patient to hospitalization, such as respiratory failure, obesity hypoventilation syndrome, and perinatal anoxia.

Of the 25 (twenty-five) patients evaluated, 15 (fifteen) were in NIV and 5 (five) patients were in NIV and were tracheostomized. The continuous positive airway pressure (CPAP) or bi-level positive airway pressure (BILEVEL) had a frequency of use at night, during sleep, or intermittent throughout the day. The other 5 (five) patients were tracheostomized and did not depend on any ventilatory support.

When guidelines on the inhalation technique were given to this group of patients, difficulties were observed regarding the administration of inhalation drugs. Patients in NIV had certain insecurity in withdrawing the support to carry out the administration of the drug, in addition to having difficulty in inspiring forcibly with a final pause, and so many preferred the nebulization instead of administration by pMDI. The adaptation and sealing of $\mathrm{pMDI}$ to the tracheostomy tube was the main difficulty found in TCT patients, added to the difficulty of communication in certain cases, due to verbal communication difficulties since tracheostomy is responsible for anatomical and physiological alterations of the respiratory system, essential for vocal production. ${ }^{7}$ The asynchronicity with the jet shot and the beginning of the inspiratory phase was a common difficulty for the groups.

The group of non-tracheostomized NIV patients $(n=15)$ received the spacer and the tidal volume inhalation maneuver was recommended to $80 \%$ of patients. This maneuver consists of not forcibly inhaling and not taking a final respiratory pause, and then performing 5 to 10 inhalations for each jet fired in the spacer. ${ }^{6}$ Since the aero-chamber used was not valved, inspiration by the mouth and exhalation by the nose was recommended to avoid exhalation inside the aero-chamber. For some patients, a siliconized mask was attached to the spacer. This mask aimed to give more safety to patients who were insecure about removing the ventilatory support or who preferred the nebulization (many mimicked the mask and the respiratory maneuver with the nebulizer and thus had more confidence in the inhalation of the drug). The mask was also inserted for those patients who could not seal the spacer's nozzle with their lips. All administrations were performed by inhalation through the oral cavity, as indicated in the medical records.

The group of tracheostomized NIV patients $(\mathbf{n}=\mathbf{5})$ showed greater heterogeneity among them. Four patients used NIV during sleep and one patient used tracheostomy support 24 hours a day. Again, the respiratory maneuver of choice was the tidal volume and the preferred access route was through tracheostomy; in $60 \%$ of cases, the patient (or companion) was trained to use the spacer attached to the mask. In all interventions, it was preferred not to administer 
the drug during NIV, because the literature shows that aeroso therapy in this situation depends on numerous parameters such as ventilatory mode, the relationship between inspiration/expiration, flow and humidity of the circuit, in addition to the parameters related to the pressurized inhaler. Non-invasive ventilation also requires a specific connector or aero-chamber that connects the inhaler to the circuit. ${ }^{8}$ Regarding the patient connected to the NIV continuously, the companion and the nursing team were instructed to remove the NIV from the patient to perform the administration of the drug directly in the tracheostomy, always monitoring their oxygen saturation. The head-up position was preferred since the sitting position improves the supply of the drug in the lower airway ${ }^{1}$

The group of tracheostomized patients without NIV $(n=5)$ also received a non-valved spacer. In $60 \%$ of the cases, the drug was administered through the tracheal orifice, while $20 \%$ received administration only through the oral cavity, and the other $20 \%$ received training for administration in both routes, according to medical orientation. There was the insertion of a plastic mask coupled to the spacer in cases when it was not possible to completely seal the tracheostomy cannula with the aero-chamber only. The mask material, similar to nebulizer masks, allowed a good fit to the neck shape and an excellent seal. The use of an isolated spacer was chosen when the cannula fixer (shoelace) and bandage generated a greater volume in the neck preventing the perfect fit of the mask or when the spacer alone generated more comfort to the patient. The respiratory maneuver of choice - together with the patient - was tidal volume (60\% of the cases). Aerosol administration through the oral cavity in tracheostomized patients, upon medical request, was done only when the patient was responsive to this route or when they would undergo decannulation and would continue the use of the inhalation device after hospital discharge.

Table 1. Demographic characteristics, clinics and interventions performed in the evaluated patients.

\begin{tabular}{|c|c|c|c|c|c|}
\hline Data & $\begin{array}{c}\text { All } \\
\mathrm{N}=25 \\
\mathrm{n}(\%)\end{array}$ & $\begin{array}{l}\text { Patients on Non-Invasive } \\
\text { Non-tracheostomized } \\
\text { N=15 n (\%) }\end{array}$ & $\begin{array}{l}\text { Mechanical Ventilation } \\
\text { Tracheostomized } \\
\text { N=5 n(\%) }\end{array}$ & $\begin{array}{l}\text { Tracheostomized patients } \\
\text { without ventilatory support } \\
\qquad N=5 n(\%)\end{array}$ & p-value \\
\hline \multicolumn{6}{|l|}{ Sociodemographic } \\
\hline Male Gender n (\%) & $15(60.0)$ & $4(26.6)$ & $2(40.0)$ & $4(80.0)$ & \\
\hline Age in years old (mean+SP) & $62.9 \pm 15.2$ & $68.8 \pm 10.4$ & $50.2 \pm 17.6$ & $57.8 \pm 19.8$ & 0.04 \\
\hline \multicolumn{6}{|l|}{ Clinical n (\%) } \\
\hline Respiratory diseases & & & & & 0.47 \\
\hline COPD & $15(60.0)$ & $10(66.6)$ & $2(40.0)$ & $3(60.0)$ & \\
\hline ASOSH & $1(4.0)$ & $1(6.6)$ & - & - & \\
\hline Asthma + ASOSH & $1(4.0)$ & $1(6.6)$ & - & - & \\
\hline COPD + ASOSH & $1(4.0)$ & $1(6.6)$ & - & - & \\
\hline COPD + Asthma & $2(8.0)$ & $1(6.6)$ & $1(20.0)$ & - & \\
\hline COPD + Neoplasia & $15(60.0)$ & - & $1(20.0)$ & - & \\
\hline COPD + other disease & $1(4.0)$ & $1(6.6)$ & - & - & \\
\hline Other diseases & $3(12.0)$ & - & $1(20.0)$ & $2(40.0)$ & \\
\hline Smoking & & & & & 0.55 \\
\hline Active & $2(8.0)$ & $1(6.6)$ & - & $1(20.0)$ & \\
\hline In abstinence & $4(16.0)$ & $3(20.0)$ & - & $1(20.0)$ & \\
\hline Ex-smoker & $11(44.0)$ & $5(33.3)$ & $4(80.0)$ & $2(40.0)$ & \\
\hline Non-smokers & $8(32.0)$ & $6(40.0)$ & $1(20.0)$ & $1(20.0)$ & \\
\hline \multicolumn{6}{|l|}{ Spirometry } \\
\hline No spirometry result & $6(24.0)$ & $1(6.6)$ & $2(40.0)$ & $3(60.0)$ & \\
\hline \multirow[t]{2}{*}{ With spirometry result } & $19(76.0)$ & $14(93.3)$ & $3(60.0)$ & $2(40.0)$ & \\
\hline & $35.2 \pm 16.1$ & $36.5 \pm 16.3$ & $36.4 \pm 14.6$ & $24.2 \pm 11.2$ & 0.64 \\
\hline Previous home use & & & & & 0.28 \\
\hline Oxygen therapy & $12(48.0)$ & $7(46.6)$ & $3(60.0)$ & $2(40.0)$ & \\
\hline Oxygen therapy + NIV & $3(12.0)$ & $3(20.0)$ & - & - & \\
\hline NIV & $2(8.0)$ & $2(13.3)$ & - & - & \\
\hline No support & $8(32.0)$ & $3(20.0)$ & $2(40.0)$ & $3(60.0)$ & \\
\hline \multicolumn{6}{|l|}{ Interventions performed n (\%) } \\
\hline Device & & & & & 0.25 \\
\hline Aero-chamber & $15(60.0)$ & $11(73.3)$ & $2(40.0)$ & $2(40.0)$ & \\
\hline Aero-chamber + mask & $10(40.0)$ & $4(26.6)$ & $3(60.0)$ & $3(60.0)$ & \\
\hline Access route & & & & & $<0.001$ \\
\hline Oral cavity & $17(68.0)$ & $15(100.0)$ & $1(20.0)$ & $1(20.0)$ & \\
\hline Tracheostomy & $7(28.0)$ & - & $4(80.0)$ & $3(60.0)$ & \\
\hline Both routes & $1(4.0)$ & - & - & $1(20.0)$ & \\
\hline Inhalation Technique & & & & & 0.35 \\
\hline Tidal Volume & $17(68.0)$ & $12(80.0)$ & $4(80.0)$ & $1(20.0)$ & \\
\hline Forced inspiration with pause & $5(20.0)$ & $1(6.6)$ & $1(20.0)$ & $3(60.0)$ & \\
\hline Both techniques & $3(12.0)$ & $2(13.4)$ & - & $1(20.0)$ & \\
\hline
\end{tabular}


In the 3 (three) groups the interventions performed by GOTTI included recommending the adoption of non-valved aerochambers (spacers) to improve the supply of the drug to the bronchi and ensure improved synchronism between the jet shot and inspiration. The use of a spacer for the administration of drugs by a pressurized inhaler increases lung deposition, when compared to the administration without a spacer. ${ }^{10}$

\section{Discussion}

A structured search in the literature identified a lack of studies in this area. Cooper and Berlinski (2017) ${ }^{11}$ evaluated the aerosol delivery using a child lung simulation model with spontaneous breathing patterns. They compared the effect on the drug delivery when pMDI was triggered by the oral cavity with a spacer and mask and when triggered by tracheostomy through a spacer designed specifically for adaptation to the cannula. The study showed that the pulmonary dose was equal or lower when the drug was administered via tracheostomy, depending on the breathing pattern. The decrease in the nominal dose is related to the retention of the aerosol particles inside the cannula, and consequently, with less pulmonary deposition.

Another study by Berlinski and colaborators $(2016)^{10}$ shows that the variables that affect the pulmonary deposition of drugs in patients undergoing tracheostomy are multiple, with a difference in the nominal dose of the drug delivered to the lungs according to the variation in respiratory pattern, type of cannula, type of aerosol device used, interface and inhalation technique employed. This study shows that the use of a major tracheostomy tube, to reduce the retention of particles inside it, and the removal of secretion from the cannula before administration of the drug are measures that can optimize the delivery of the drug. Regarding the inhalation technique, the authors recommend the use of an interface, aero-chamber or tracheal T-tube, alongside the pMDI; and training the patient for deep and slow breathing while receiving the drug through the inhalation route. The authors do not recommend the use of the assisted technique, which consists in increasing the tidal volume and respiratory flow with a resuscitation bag during inhalation from aerosol since there is a reduction in the pulmonary deposition.

A study of a series of cases from 1999,13 in a population of tracheostomized patients, showed that the use of a spacer associated with the mask was used in practice when there is no availability of a specific spacer that fits the cannula. In this study, a child mask was used to come up with the tracheal tube sealing.

For inhalation administration of pMDI drugs to patients on noninvasive mechanical ventilation, the current daily practice consists of disconnection of the device and usual inhalation of the drug through the oral cavity. ${ }^{8,10}$ When this withdrawal is not possible, the PMDI must be adapted to the mask or circuit of the device and triggered at the beginning of the inspiratory phase. ${ }^{8}$ Multiple factors influence aerosol therapy during NIV, among them: the use of aerochamber adaptable to the system, device settings, position of leak ports, humidification, synchrony with the inspiratory phase, type of used interface and patient-related factors such as type of airway obstruction and support tolerability. ${ }^{10,14}$

Our study showed results similar to those of cited studies. The studies recommend the use of aero-chamber for inhalation therapy in tracheostomized patients and the absence of a specific spacer for connection to the tracheal cannula one can use siliconized masks to facilitate the sealing and avoid the aerosol leak to the exterior. For patients under non-invasive mechanical ventilation, it is recommended, when possible, to administer the medication through the oral cavity with aero-chamber, as usual, since in our study casuistry, all patients used NIV intermittently throughout the day.

The authors recommend deep and slow breathing while the patient is receiving the medicine by inhalation, which can be performed both in tidal volume technique and in forced inspiration with a final pause. In our experience, the tidal volume technique was preferred over the other technique because it seems more comfortable for patients with severe airflow obstruction.

\section{Conclusion}

For the best administration of inhalation drugs and the best therapeutic effect, it is recommended to pay attention to the measures that bring the greatest comfort and safety to the patient. Pressurized inhalers are types of multi-dose presentations whose indiscriminate use can lead to toxicity and serious adverse effects, hence the importance of an inhalation technique.

Patients with tracheostomy and/or on non-invasive mechanical ventilation using inhalation therapy present relevant clinical features that justify specialized care, and often pose challenges to the care team. There is a need for further studies to improve the inhalation administration of drugs in this population.

\section{Funding sources}

This work was supported by the Research and Events Incentive Fund (Fundo de Incentivo à Pesquisa e Eventos, FIPE) of the Clinical Hospital of Porto Alegre and by Extension Program from the Federal University of Rio Grande do Sul (Universidade Federal do Rio Grande do Sul, UFRGS).

\section{Collaborators}

Asturian K, a scholarship holder during the graduation of the Inhalation Technique Orientation Group (GOTTI), has a special interest in the administration of inhalation drugs in special contexts. She has developed the work with tracheostomized and NIV patients at the Clinical Hospital of Porto Alegre and was responsible for the study design, total text writing, tabulation, and data analysis and bibliography evaluation. Ferreira MA, pneumologist, GOTTI's preceptor, responsible for the creation of low-cost handmade aero-chambers at the Clinical Hospital of Porto Alegre. She was responsible for guiding the work, designing the study, writing the text and critically reviewing the intellectual content.

\section{Acknowledgments}

To the Clinical Hospital of Porto Alegre and to the Extension Program from the Federal University of Rio Grande do Sul (UFRGS) for enabling great learning in this teaching hospital. To Professor Dr. Leila Beltrami Moreira for her support to the GOTTI and to the other scholarship holders who dedicated themselves to the group.

\section{Conflict of interest statement}

The authors declare there are no conflicts of interests regarding this article. 


\section{References}

1. Dhand R, Guntur VP. How Best to Deliver Aerosol Medications to Mechanically Ventilated Patients. Clinics in Chest Medicine. 2008;29(2):277-96.

2. Ricz HMA, Filho FV de M, Freitas LCC, et al. Traqueostomia. In: Simpósio: Fundamentos em Clínica Cirúrgica. 2011; 44(1):63-9.

3. Soares MCCX, Westphal FL, Lima LC, et al. Elaboração de protocolo de condutas em traqueostomias no hospital referência de tratamento do câncer do Amazonas. Revista do Colégio Brasileiro de Cirurgiões. 2018;45(4):1-11.

4. Vianna A, Palazzo RF, Aragon C. Tracheostomy: an up-to-date review. Pulmão RJ. 2011;20(21):39-42.

5. Sanchis J, Corrigan C, Levy ML, et al. Inhaler devices- From theory to practice. Respiratory Medicine. 2013;107(4):495-502.

6. Ministerio da Saúde. Protocolo Clínico e Diretrizes Terapêuticas Doença Pulmonar Obstrutiva Crônica. [Brasil]; 2013.

7. Helena R, Gomes S, Carla M, et al. A comunicação do paciente traqueostomizado: uma revisão integrativa. Speech, Language, Hearing Sciences an Educucation Journal. 2016;18(5):1251-9.

8. Maccari JG, Teixeira C, Gazzana MB, et al. Terapia inalatória em ventilação mecânica. Jornal Brasileiro de Pneumologia. 2015;41(5):467-72.

9. Dhand R. Aerosol Therapy in Patients Receiving Noninvasive Positive Pressure Ventilation. Journal of Aerosol Medicine Pulmonay Drug Delivery. 2012;25(2):63-78.

10. Berlinski A, Cooper B. Oronasal and Tracheostomy Delivery of Soft Mist and Pressurized Metered-Dose Inhalers With Valved Holding Chamber. Respiratory Care. 2016;61(7):913-9.

11. Berlinski A, Ari A, Davies P, et al. Workshop Report: Aerosol Delivery to Spontaneously Breathing Tracheostomized Patients. Journal of Aerosol Medicine Pulmonary Drug Delivery. 2017;30(0):1-16.

12. Mirza S, Hopkinson L, Malik TH, et al. The use of inhalers in patients with tracheal stomas or tracheostomy tubes. Journal of Laryngology and Otology. 1999;113:762-4.

13. Reychler G, Michotte J. Development challenges and opportunities in aerosol drug delivery systems in non-invasive ventilation in adults. Expert Opinion on Drug Delivery. 2019;16(2):153-162. 